\title{
Human adenovirus type 8 epidemic keratoconjunctivitis with large corneal epithelial full-layer detachment: an endemic outbreak with uncommon manifestations
}

\author{
This article was published in the following Dove Press journal: \\ Clinical Ophthalmology \\ 27 May 2015 \\ Number of times this article has been viewed
}

\section{Yueh-Chang Lee' \\ Nancy Chen' \\ I-Tsong Huang $2-4$ \\ Hui-Hua Yang ${ }^{2}$ \\ Chin-Te Huang' \\ Li-Kuang Chen ${ }^{2-5}$ \\ Min-Muh Sheu ${ }^{1,6,7}$ \\ 'Department of Ophthalmology, \\ ${ }^{2}$ Taiwan CDC Collaborating \\ Laboratories of Virology, ${ }^{3}$ Department \\ of Laboratory Medicine, Buddhist \\ Tzu-Chi General Hospital, Hualien, \\ Taiwan; ${ }^{4}$ Graduate Institute of \\ Medical Sciences, ${ }^{5}$ Department of \\ Laboratory Diagnosis, ${ }^{6}$ Department of Ophthalmology and Visual Science, \\ Tzu-Chi University, Hualien, Taiwan; \\ ${ }^{7}$ Department of Ophthalmology, \\ Mennonite Christian Hospital, \\ Hualien, Taiwan}

Correspondence: Min-Muh Sheu

Department of Ophthalmology,

Mennonite Christian Hospital,

44 Min-Chuan Road, Hualien, Taiwan

Tel +886970332336

Fax +8863824I603

Email minmuhsu@gmail.com

\begin{abstract}
Epidemic viral conjunctivitis is a highly contagious disease that is encountered yearround. The causative agents are mainly adenoviruses and enteroviruses. It occurs most commonly upon infection with subgroup D adenoviruses of types 8,19 , or 37 . For common corneal involvement of human adenovirus type 8 epidemic keratoconjunctivitis, full-layer epithelial detachment is rarely seen. Herein, we report three cases of epidemic keratoconjunctivitis during an outbreak which manifested as large corneal epithelial full-layer detachment within a few days. The lesions healed without severe sequelae under proper treatment. The unique manifestation of this outbreak may indicate the evolution of human adenovirus type 8 .
\end{abstract}

Keywords: EKC, HAdV-8, cornea, virology, epidemic viral conjunctivitis

\section{Introduction}

During a 12-week period (July 31, 2013 to October 27, 2013), more than 100 patients with acute conjunctivitis visited Department of Ophthalmology at the Buddhist Tzu Chi General Hospital, Hualien, Taiwan, and more cases possibly went unreported by the local clinics in Hualien, Taiwan. Twenty cases were sent to the contract virology lab for analysis, of which 16 cases were shown to be adenovirus-positive by polymerase chain reaction (PCR) and virus isolation. Of these 16, eight cases were confirmed to be human adenovirus type $8(\mathrm{HAdV}-8)$ by hexon sequencing, while four among them manifested as large corneal epithelial full-layer detachment. The four patients were surveyed and were found to have family members suffering from conjunctivitis during the outbreak, and were later confirmed to have HAdV-8.

HAdV-8 epidemic keratoconjunctivitis (EKC) commonly involves the cornea, ${ }^{1}$ however full-layer epithelial detachment is uncommon. Herein, we report three cases of EKC during an endemic outbreak which manifested as large corneal epithelial full-layer detachment within a few days. Although the lesions healed without severe sequelae under adequate treatment, the manifestation of this outbreak may indicate the evolution of HAdV-8.

\section{Case descriptions \\ Case I}

A healthy 44-year-old male with congested conjunctiva and watery discharge of both eyes accompanied by a burning foreign-body sensation and blurred vision visited 
our clinic. His ocular history was unremarkable, and he had had 20/20 vision before this episode. On examination, his eyelids were found to be erythematous and edematous, the conjunctivae were hyperemic and chemotic, and there were more follicles in the inferior palpebral conjunctivae. Bilateral large tender pre-auricular lymph nodes were palpable.

The patient was then treated empirically for EKC. After 4 days ( 9 days after the initial symptoms), the cornea of the left eye had a large area of circular epithelial defect with debris coating the surface (Figure 1A). Prednisolone acetate 1\% eye drops and artificial tears were prescribed in addition to antibiotics. The next day, the epithelial defect had widened with an overhanging edge (Figure 1B), and the cornea of the right eye started to present with multiple full-layer epithelial defects (Figure 1C), but much smaller in size than the ones in the left eye. Sixteen days after the appearance of the initial symptoms, the defect of the corneas re-epithelialized; however, subepithelial corneal infiltrates were observed in both eyes (Figure 1D).

\section{Case 2}

A 15-year-old male presented with watery eyes that caused discomfort after a train trip. Conjunctival injection and follicular reaction were found. There was also an enlarged tender pre-auricular lymph node on the right side.

He was treated empirically for EKC, however full-layer cornea epithelial detachment with a scrolling over-hanging edge appeared in his left eye after 5 days (Figure 2A). Artificial tears and eye drops with dexamethasone were added, and the epithelial defect started to heal rapidly over the next 2 days (Figure 2B).

\section{Case 3}

A 5-year-old female presented to our emergency room with pain, tearing, and photophobia in bilateral eyes for 1 week. She had a common cold with cough and sputum a week earlier followed by red eyes and watery discharge. Some of her kindergarten schoolmates also had red eyes during the same period. Severe papillary congestion with patchy subconjunctival hemorrhage (SCH) in the conjunctivae, and an epithelial defect on the cornea of her right eye were found (Figure 3A). Her left eye showed mild papillary congestion with some punctate keratitis.

She was treated with combined antibiotics/steroids and lubricants, and the large epithelial defect started to heal after 3 days (Figure 3B).
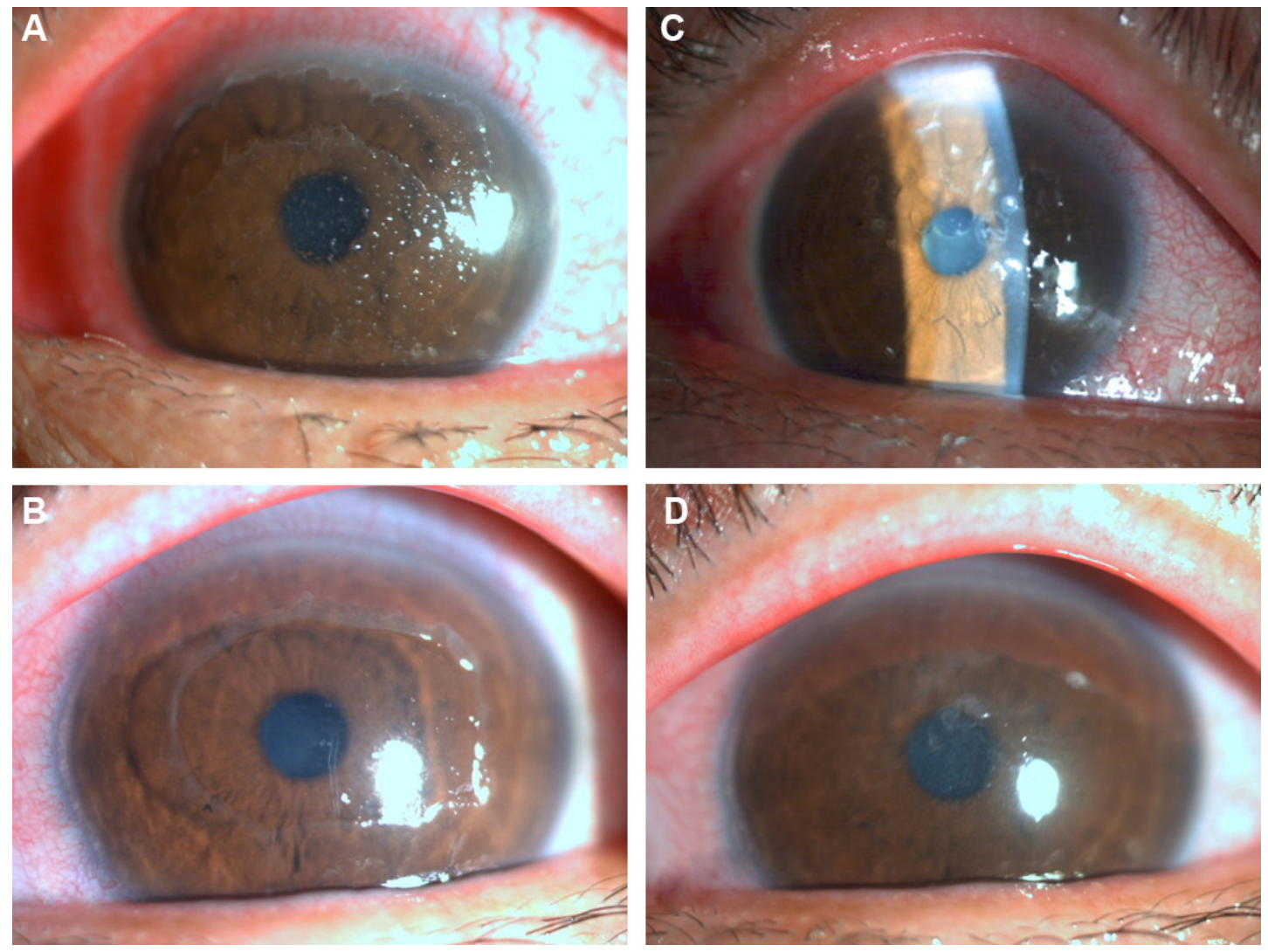

Figure I Case I: a 44-year-old male.

Notes: (A) Nine days after the appearance of the initial symptoms. The cornea of the left eye had a large area of circular epithelial defects with an irregular surface. (B) The epithelial defect widened with an overhanging edge on the tenth day. (C) The cornea of the right eye started to present with multiple full-layer epithelial defects, smaller than the ones in the left eye. (D) The previous defect of the cornea re-epithelialized, and subepithelial corneal infiltrates were observed. 

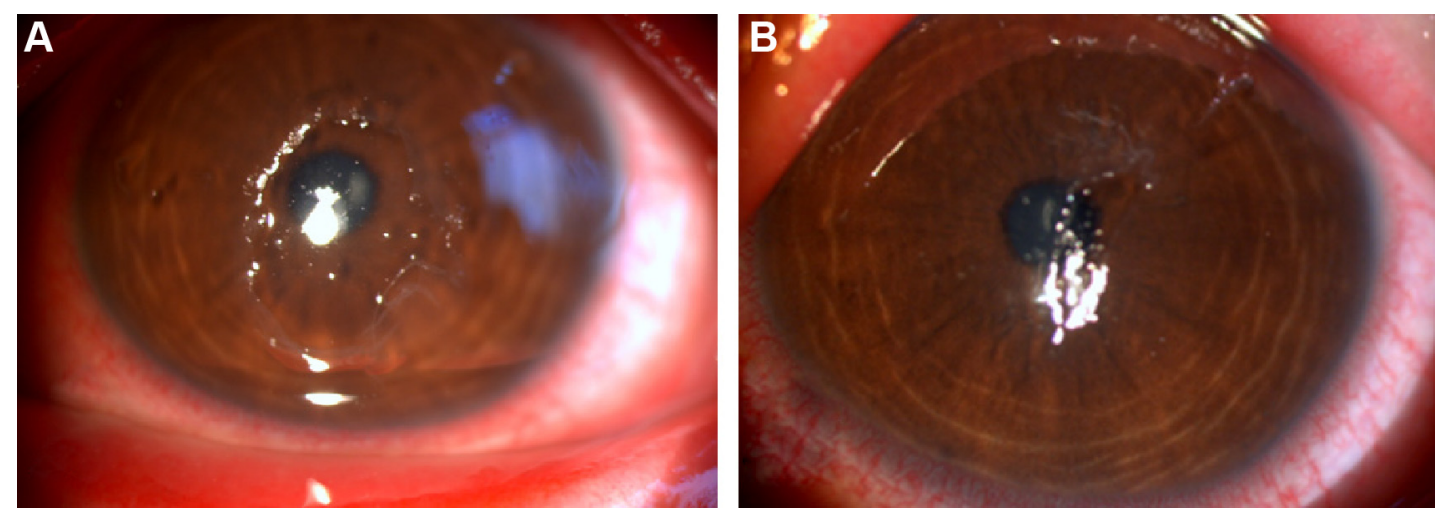

Figure 2 Case 2: A 15-year-old male.

Notes: (A) Full-layer cornea epithelial detachment with a scrolling over-hanging edge appeared in the left eye of a I5-year-old male. (B) The epithelial defect started to heal rapidly during the next 2 days.

\section{Materials and methods}

In the above cases, a conjunctival swab, sloughed-off cornea epithelial tissue, and throat swab were collected, in each case. Rapid adenovirus detection was performed by PCR using a primer for the hexon gene, and genotype identification was done using direct sequencing (using a ABI Prism 3730) followed by the BLASTN (Basic Local Alignment Search Tool for Nucleotides) program in the National Center for Biotechnology Information (NCBI) database. ${ }^{2}$ HAdV-8 was then identified due to $98 \%$ nucleotide identity to the human adenovirus D strain (accession number KF429751). The virus was successfully isolated and confirmed by immunofluorescence assay (Figure 4) using LIGHT DIAGNOSTICS ${ }^{\text {TM }}$ Adenovirus Antibody reagent (catalog number 3105; Merck Millipore, Billerica, MA, USA).

\section{Discussion}

Epidemic viral conjunctivitis is a highly contagious disease that is encountered year-round. The causative agents are mainly adenoviruses and enteroviruses. EKC occurs most commonly

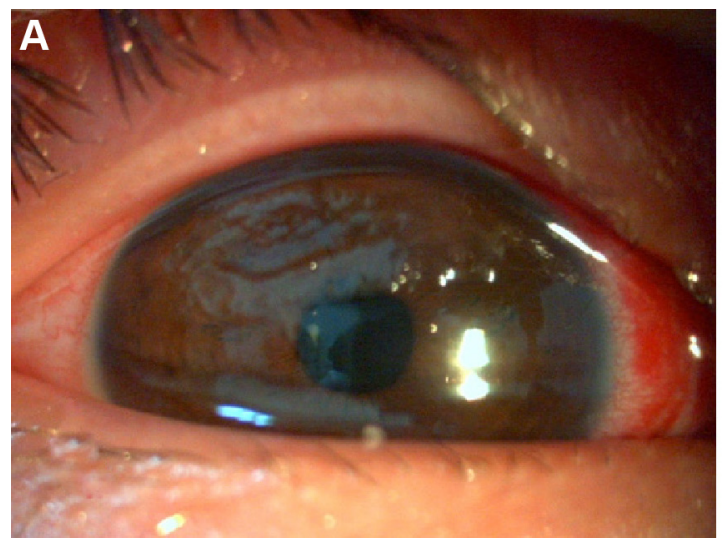

upon infection with subgroup D adenoviruses of type 8, 19, or 37 , although the predominant viruses isolated in each endemic outbreak vary by geographic area. In a study by Chang et al, ${ }^{3}$ Ad8, Ad19, and Ad37 were the most commonly isolated adenoviruses from 1980 to 1997 in southern Taiwan, and the severity of the host symptoms of SCH and keratitis increased along with the increasing incidence of Ad19 and Ad37 during that time period. Two new human adenovirus types previously mistyped as other adenoviruses that cause EKC were recently identified and named HAdV-53 and HAdV-54. ${ }^{4-6}$ Re-determination of virus types between 1990 and 2009 in Japan showed that isolations of HAdV-54 had increased since 1995 and exceeded those of HAdV-8 in 2000-2005. ${ }^{7}$ EKC has been reported to be the most common viral disease of the eye and results in significant morbidity, health care costs, and even temporary closure of clinical facilities. ${ }^{8,9}$ Therefore, high surveillance is mandatory even for general practitioners.

Among patients with EKC, common clinical signs are conjunctival congestion, pseudomembrane formation, edematous lid, and even inflammatory ptosis. ${ }^{10,11} \mathrm{SCH}$, which

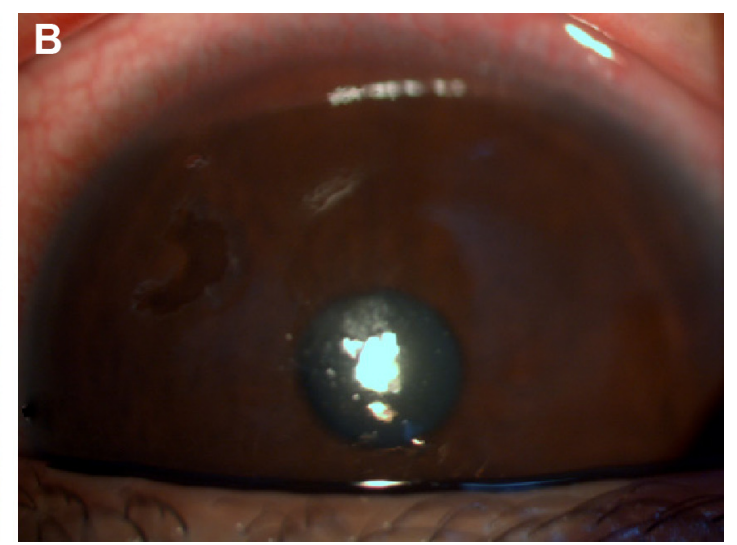

Figure 3 Case 3: a 5-year-old female.

Notes: (A) Severe papillary congestion with patchy subconjunctival hemorrhage in the conjunctiva and an epithelial defect on the cornea in the right eye of a 5-year-old female. (B) The large epithelial defect started to heal after 3 days. 

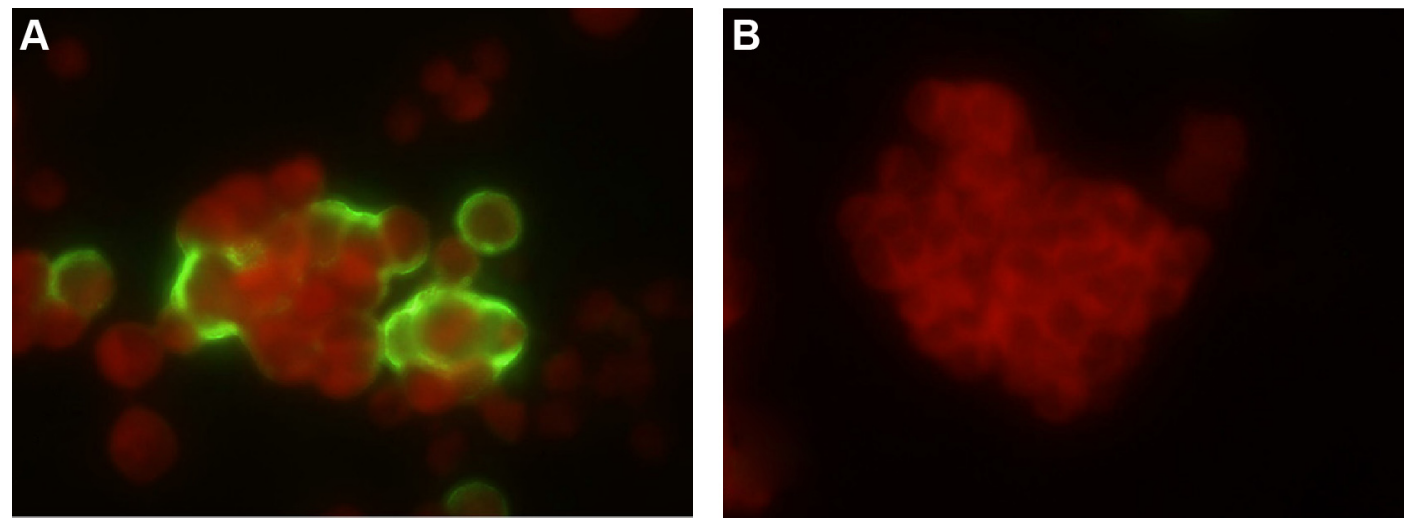

Figure 4 Detection of adenovirus in the HEp-2 cells derived from swab samples of patients by indirect immunofluorescence assay. The cytoplasm and nuclei were stained red by Evans blue, and green fluorescent signals were on adenovirus-infected cells.

Notes: (A) Adenovirus-infected cells were detected with anti-adenovirus antibody. (B) Uninfected cells were the negative control.

is a hallmark feature of enterovirus-associated acute hemorrhagic conjunctivitis, started to emerge as a sign of EKC in the 1980s. ${ }^{3,12}$ Occasionally, the intense conjunctival inflammation may lead to permanent symblepharon formation and dry eye. ${ }^{13}$ Corneal involvement includes superficial epithelial keratitis, ${ }^{14}$ small epithelial punctate that tends to enlarge, and the development of subepithelial infiltrates. ${ }^{10,11,13,15}$ The subepithelial corneal infiltrates may persist for 2 years and result in permanent scarring. ${ }^{12}$ Chang et al studied changes in the clinical presentation of EKC eyes over 18 years, ${ }^{3}$ and concluded that the presence of $\mathrm{SCH}$, keratitis, and preauricular adenopathy had aggravated over that time period, whereas the severity of conjunctivitis had increased along with $\mathrm{Ad} 8$ genotypes $\mathrm{Ad} 8 \mathrm{C}$ to $\mathrm{Ad} 8 \mathrm{H}$. In addition, the incidence of symblepharon and subepithelial corneal infiltration decreased significantly. Hence, the evolution of genotypes may correlate with the changes in clinical presentations and new epidemic outbreaks. ${ }^{3,7,16}$

Large corneal epithelial defects in human adenovirus infections are rare. Dawson and colleagues reported two HAdV-8 EKC patients with large central corneal erosions with SCH in $1972,{ }^{17}$ both of whom had predisposing ocular conditions including blepharitis and keratitis sicca. Two of our patients presented with SCH during the EKC infection, however neither of them had chronic ocular diseases. Darougar et al reported in 1983 that among 82 patients with adenovirus keratoconjunctivitis, ${ }^{14}$ two had severe epithelial involvement with considerable erosion and were identified as having serotype Ad8 infection.

In our three patients with EKC that manifested as fulllayer epithelial detachment, HAdV-8 was rapidly identified as the causative agent by PCR sequencing and further confirmed with virus isolation. With the increasing incidence of this manifestation, large epithelial defects can be considered to be a notable feature of HAdV-8 EKC. Since virus replication and immunological responses in the corneal epithelial cells could have contributed to the profound corneal detachment, further studies are needed to elucidate the underlying mechanism. The decreased incidence of symblepharon and subepithelial cornea infiltration, along with the reported increased empirical use of steroid eye drops in the treatment of EKC, ${ }^{3}$ may also suggest that immunological cascades play a crucial role in the pathogenesis. ${ }^{18}$ Given that the HAdV-8 genotype has been constantly evolving over the years, ${ }^{3,7}$ further investigation at the molecular biology level is needed to elucidate whether the clinical presentations result from changes in virulence along with changes in genome sequence.

\section{Disclosure}

The authors declare no conflicts of interest in this work.

\section{References}

1. Tabbara KF, Omar N, Hammouda E, et al. Molecular epidemiology of adenoviral keratoconjunctivitis in Saudi Arabia. Mol Vis. 2010;16: 2132-2136.

2. Gröndahl B, Puppe W, Hoppe A, Kühne I, Weigl JA, Schmitt HJ. Rapid identification of nine microorganisms causing acute respiratory tract infections by single-tube multiplex reverse transcription-PCR: feasibility study. J Clin Microbiol. 1999;37(1):1-7.

3. Chang CH, Lin KH, Sheu MM, Huang WL, Wang HZ, Chen CW. The change of etiological agents and clinical signs of epidemic viral conjunctivitis over an 18-year period in southern Taiwan. Graefes Arch Clin Exp Ophthalmol. 2003;241(7):554-560.

4. Ishiko H, Shimada Y, Konno T, et al. Novel human adenovirus causing nosocomial epidemic keratoconjunctivitis. J Clin Microbiol. 2008;46(6): 2002-2008.

5. Akiyoshi K, Suga T, Fukui K, Taniguchi K, Okabe N, Fujimoto T. Outbreak of epidemic keratoconjunctivitis caused by adenovirus type 54 in a nursery school in Kobe City, Japan in 2008. Jpn J Infect Dis. 2011; 64(4):353-355

6. Ishiko H, Aoki K. Spread of epidemic keratoconjunctivitis due to a novel serotype of human adenovirus in Japan. J Clin Microbiol. 2009;47(8): 2678-2679. 
7. Kaneko H, Suzutani T, Aoki K, et al. Epidemiological and virological features of epidemic keratoconjunctivitis due to new human adenovirus type 54 in Japan. Br J Ophthalmol. 2011;95(1):32-36.

8. Piednoir E, Bureau-Chalot F, Merle C, Gotzamanis A, Wuibout J, Bajolet O. Direct costs associated with a nosocomial outbreak of adenoviral conjunctivitis infection in a long-term care institution. $\mathrm{Am}$ J Infect Control. 2002;30(7):407-410.

9. Chang C, Sheu M, Chern C, Lin K, Huang W, Chen C. Epidemic keratoconjunctivitis caused by a new genotype of adenovirus type 8 (Ad8)-a chronological review of Ad8 in Southern Taiwan. Jpn J Ophthalmol. 2001;45(2):160-166.

10. Meyer-Rüsenberg B, Loderstädt U, Richard G, Kaulfers PM, Gesser C. Epidemic keratoconjunctivitis: the current situation and recommendations for prevention and treatment. Dtsch Arztebl Int. 2011;108(27):475-480.

11. Viney KA, Kehoe PJ, Doyle B, et al. An outbreak of epidemic keratoconjunctivitis in a regional ophthalmology clinic in New South Wales. Epidemiol Infect. 2008;136(9):1197-1206.

12. Chang CH, Sheu MM, Lin KH, Chen CW. Hemorrhagic viral keratoconjunctivitis in Taiwan caused by adenovirus types 19 and 37: applicability of polymerase chain reaction-restriction fragment length polymorphism in detecting adenovirus genotypes. Cornea. 2001;20(3):295-300.
13. Butt AL, Chodosh J. Adenoviral keratoconjunctivitis in a tertiary care eye clinic. Cornea. 2006;25(2):199-202.

14. Darougar S, Grey RH, Thaker U, McSwiggan DA. Clinical and epidemiological features of adenovirus keratoconjunctivitis in London. Br J Ophthalmol. 1983;67(1):1-7.

15. Dosso AA, Rungger-Brändle E. Clinical course of epidemic keratoconjunctivitis: evaluation by in vivo confocal microscopy. Cornea. 2008;27(3):263-268.

16. Nakamura M, Hirano E, Kowada K, et al. Surveillance of adenovirus D in patients with epidemic keratoconjunctivitis from Fukui Prefecture, Japan, 1995-2010. J Med Virol. 2012;84(1):81-86.

17. Dawson CR, Hanna L, Togni B. Adenovirus type 8 infections in the United States IV. Observations on the pathogenesis of lesions in severe eye disease. Arch Ophthalmol. 1972;87(3):258-268.

18. Rajaiya J, Chodosh J. New paradigms in infectious eye disease: adenoviral keratoconjunctivitis. Arch Soc Esp Oftalmol. 2006;81(9):493-498. English and Spanish.
Clinical Ophthalmology

\section{Publish your work in this journal}

Clinical Ophthalmology is an international, peer-reviewed journa covering all subspecialties within ophthalmology. Key topics include: Optometry; Visual science; Pharmacology and drug therapy in eye diseases; Basic Sciences; Primary and Secondary eye care; Patient Safety and Quality of Care Improvements. This journal is indexed on

Submit your manuscript here: http://www.dovepress.com/clinical-ophthalmology-journal

\section{Dovepress}

PubMed Central and CAS, and is the official journal of The Society of Clinical Ophthalmology (SCO). The manuscript management system is completely online and includes a very quick and fair peer-review system, which is all easy to use. Visit http://www.dovepress.com/ testimonials.php to read real quotes from published authors. 